\title{
Interaction between bottlenose dolphin (Tursiops truncatus) and trammel nets in the Archipelago de La Maddalena, Italy
}

\author{
Pennino M. Grazia ${ }^{1,{ }^{*}}$, Rotta A. ${ }^{2}$, Pierce Graham J. ${ }^{3,4}$, Bellido Jose M. ${ }^{3,5}$
}

\author{
1 Institut de Recherche pour le Développement (IRD), UMR EME 212 (IRD//fremer/Université \\ Montpellier 2) Centre de Recherche Halieutique Méditerranéenne et Tropicale, Avenue Jean Monnet, \\ B.P. 171, 34203, Sète Cedex, France \\ 2 Dipartimento di Biologia Animale Facoltà di Medicina Veterinaria, Università di Sassari, Sassari, Italy \\ 3 Oceanlab, School of Biological Sciences, University of Aberdeen, Main Street, Newburgh, \\ Aberdeenshire, AB41 6AA, UK \\ ${ }^{4}$ CESAM \& Departamento de Biologia, Universidade de Aveiro, 3810-193, Aveiro, Portugal \\ 5 Instituto Español de Oceanografía, Centro Oceanográfico de Murcia, Murcia, Spain \\ *Corresponding author : Grazia M. Pennino, email address : maria-grazia.pennino@ird.fr
}

\begin{abstract}
:
Interactions between bottlenose dolphins (Tursiops truncatus) and fisheries are an increasing problem in the Mediterranean and effective management measures are needed. In order to assess the impact of dolphin interactions on artisanal trammel nets, we examine 354 fishing operations performed in waters of the Archipelago de La Maddalena (Italy). We evaluate whether interactions were related to the species composition of the catch and, using the local commercial value of the target species, we assess whether there was a real economic loss for fishermen. Bayesian models and partial correspondence analysis were used to determine the extent to which dolphin interactions and habitat differences contributed to variation in the species composition of catches. CPUE for fishing operations with no dolphin interactions was significantly higher than that for operations with dolphin interactions, although clearly this does not confirm a direct causal link, and associated economic loss was estimated to be non-significant. Geographic location, season, depth of seabed, moon phase, and mesh size were all important factors affecting the amount and species composition of the catch. Our results suggest that it is likely that these differences in species composition are due to a mixture of habitat and dolphin-induced effects.
\end{abstract}




\section{INTRODUCTION}

52 Fish are among the most important natural resources of the world, but because

53 of technical improvements in catching power and development of trade,

54 fisheries have reached an unprecedented level of exploitation (Jackson et al.

55 2001; Ormerod 2003; Rocklin et al. 2009). The increasing trend in the 56 percentage of overexploited, depleted and recovering marine fish stocks

57 reduces the amount of prey available for natural predators (Bearzi 2002).

59 Food availability is a critical factor which limits the distribution and numbers of 60 animal populations in the oceans. The relationship between predators and their

61 prey can be disturbed by intensive commercial fishing (Mcmahon et al. 2005).

62 Take, for instance, the ecological crisis in the Barents Sea ecosystem over the 63 past 30 years, related to the overfishing of stocks of capelin (Mallotus villosus, 64 Müller, 1776) and herring (Clupea harengus, Linnaeus, 1758) (Hamre 2003).

65 Haug et al. (2002) showed that, following a collapse in the capelin stock in the 66 mid-90s, minke whales (Balaenoptera acutorostrata, Lacépède, 1804) foraging 67 in the northern Barents Sea switched from a capelin-dominated diet to a diet 68 almost completely comprised of krill (Euphausia spp.).

70 Steller sea lions (Eumetopias jubatus, Schreber, 1776) in the North Pacific

71 provide another example of how a marine mammal population can be affected

72 by overfishing of forage food supplies. Several studies have shown that Steller

73 sea lion in Alaskan waters and the Aleutian Islands were nutritionally stressed

74 because of a reduction in overall prey abundance (Trites \& Donnelly 2003;

75 Merrick et al. 2011). As a result these predators have begun to diversify their 
76 feeding behavior by introducing other types of prey into their diet (Milette \&

77 Trites 2003).

79 In general, when faced with food shortages or poor quality food, marine

80 mammals will modify their behaviour to reduce nutritional stress and conserve

81 energy and body condition (Trites \& Donnelly 2003) and, consequently, direct

82 competitive interactions with fishing activity have increased (Northridge 1984;

83 Fertl \& Leatherwood 1997, Bearzi 2002).

85 In the Mediterranean Sea, interactions between dolphins and fishing activity 86 have been reported since more than a century ago (see Barone 1895, for one

87 of the most earliest reports). Recently, in the context of declining fish stocks, 88 the fishing industry has increasingly viewed these interactions as a problem, 89 particularly so for small-scale fisheries (Díaz-López 2006; Lauriano et al. 2004, 90 2009; Rocklin et al. 2009).

92 Dolphins have learned that the catch of gillnet and trammel nets represents a 93 new, easily accessible, food resource (Reeves et al. 2001). They remove the 94 fish entangled in nets and damage the fishing gear, by tearing holes in the nets

95 as they attempt to remove fish (Lauriano et al. 2004; Cox et al. 2003), resulting 96 in reductions in the quantity and/or quality of the catch (Bearzi 2002; Rocklin et 97 al. 2009), and consequent economic (time, money, or gear) losses by fishers 98 (Gönener \& Özdemir 2012). In addition the contact between dolphins and 99 fishing activity increases the likelihood that dolphins will suffer serious injury or 100 death due to entanglement (Wells \& Scott 1994; Gorzelany 1998; Wells et al. 
103 However, some interactions between dolphins and fisheries have been 104 described as cooperative (Busnel 1973; Pryor et al. 1990; Neil 2002) and 105 sometimes higher catch have been reported when dolphins were present in the 106 fishing areas (Silva et al. 2002; Rocklin et al. 2009). Other indirect advantages 107 may also arise from the fact that dolphins make an area more attractive for 108 tourism, thus providing economic benefits (e.g., increased demand for seafood) 109 that may positively influence local fisheries (Bearzi 2002).

111 Moreover, most marine mammals, being top predators, are essential 112 components of healthy and sustainable ecosystems and their ecological 113 importance and conservation must be kept in mind (Estes et al. 1998), as 114 recognised by the EU Marine Strategy Framework Directive.

116 The main types of fishing gear used in coastal Mediterranean waters where 117 conflict with dolphins has been reported are bottom-set trammel nets and 118 gillnets, although dolphins also interact with trawl nets and with small purse 119 seines targeting pelagic schooling fish (Reeves et al. 2001). Several studies 120 have been carried out concerning the competitive interactions between marine 121 mammals and fisheries, e.g. in Greece (Conides \& Papacostantinou 2001), 122 Spain (Brotons et al. 2008; Gazo et al. 2008), Tunisia (Naceur et al. 2004), 123 Corsica (Rocklin et al. 2009) and Italy (Reeves et al. 2001).

125 Despite several reports of the occurrence of depredation by dolphins on 
126 trammel net fisheries along Sardinian coasts (Italy), few attempts have been

127 made to evaluate the phenomenon (Lauriano et al. 2004; Díaz-Lopez 2006).

128 The lack of information on the frequency and amount of depredation, or on its

129 economic effects, makes any effort to solve or manage the conflict very difficult

130 (Lauriano et al. 2009).

132 The Archipelago de La Maddalena, located in the northeast of the island of

133 Sardinia, is part of the Pelagos Cetacean Sanctuary, the biggest "Marine

134 Protected Area" (MPA) in the Mediterranean Sea (about 87,500 km²), extending

135 over waters belonging to three European countries (France, Italy and Monaco).

136 For a complete report on the Pelagos Cetacean Sanctuary and its history, see

137 Notarbartolo di Sciara et al. 2008.

139 Artisanal fisheries around the Archipelago de La Maddalena operate within the 140 coastal waters of the continental shelf, mainly between the coast and the 100 $141 \mathrm{~m}$. depth contour, coinciding spatially with areas used by dolphins and 142 temporally with the diurnal feeding period of dolphins and thus increasing the 143 probability of the interaction between dolphin and fisheries (Wise et al. 2007).

145 Local artisanal fishers have expressed concern about reduced catches, 146 increased fishing time and gear damage caused by dolphins, highlighting the 147 importance of this problem for trammel nets that are used to target red mullet 148 (Mullus surmuletus, Linnaeus, 1758) and cuttlefish (Sepia officinalis, Linnaeus, 149 1758). Resolution of such conflicts requires baseline quantitative information 150 on the impact of dolphin depredation on fisheries (Matthiopoulos et al. 2008). 
152 Here we present a three-step approach to evaluate these interactions in the 153 Archipelago de La Maddalena. Firstly, we evaluate whether the interaction of 154 dolphins with trammel fishing operations in the Archipelago de La Maddalena 155 involves a real negative impact on fishing catches, by modelling the catch per 156 unit effort (CPUE) with respect to occurrence of dolphin interactions, 157 environmental covariates and characteristics of the fishing operations, using 158 Bayesian models. Secondly, we evaluate the hypothesis that the presence of 159 dolphins during fishing operations could alter the composition of the catch at 160 the species level. For this purpose, Partial Correspondence Analysis was used to 161 evaluate how much of the variation in species composition of catches is caused 162 by dolphin interaction, environment or a combination of both. In addition, 163 based on the local commercial value of the target species (per $\mathrm{kg}$.), we assess 164 whether there is a real economic loss to fishermen. Finally, we used Bayesian 165 logistic regression to determine the extent to which habitat differences 166 contributed to the occurrence of dolphin interactions.

\section{MATERIALS AND METHODS}

\section{Study area}

170 This study was carried out in waters within 3 miles of the coast of Archipelago 171 de La Maddalena. The entire area is included within a National Park located in 172 the strait of Bonifacio, between the islands of Sardinia and Corsica, and is part 173 of the Pelagos Cetacean Sanctuary, established by Italy, France and Monaco in 1741999. 
176 The Maddalena area is characterized by rocky and sandy bottoms extensively

177 covered with Posidonia (Posidonia oceanica, Delile, 1813) seagrass beds, with 178 water depth ranging from 0 to $70 \mathrm{~m}$. The location of the Archipelago inside the 179 "Bocche of Bonifacio" causes a high hydrodynamism that, associated with 180 shallow depth of the channel and limited tidal range, is responsible for the very 181 clean water which characterizes the area. The general aspect of the coast is 182 indented, characterized by small promontories, bays and narrow channels. The 183 topography of the bottom is variable with large cracks, reefs and small islands 184 (Esposito et al. 1992).

Only 18 fishing boats based in La Maddalena National Park are permitted to undertake artisanal fishing activities in the area. These are small vessels, with 188 length from 6 to $12 \mathrm{~m}$., which employ predominantly bottom-set triple panel gill nets (known as trammel nets) consisting of a small mesh inner and two large mesh outer panels of monofilament net mounted together on the same frame 191 ropes.

193 Occasionally, single panel gillnets or different types of gillnets combined in a 194 single gear (e.g. a trammel net combined with a single net) are used. Fishing 195 takes place throughout the year using nets with a stretched mesh size from 20 196 to $62 \mathrm{~mm}$. (knot to knot), set at depths ranging from $5 \mathrm{~m}$. to $70 \mathrm{~m}$., with soak 197 times from 30 minutes to 7 hours, concentrating fishing effort in the early 198 morning. The net mesh size is chosen based on the main targeted species. 199 Between June and December, red mullet (Mullus surmuletus) is targeted using 200 a mesh of between 9 and 12 nodes per $25 \mathrm{~cm}$. of rope. Common cuttlefish 
201 (Sepia officinalis) is targeted between March and June using a mesh of between

2027 and 9 nodes. Between April and August, European spiny lobster (Palinurus 203 elephas, Fabricius, 1787) is targeted using mesh with 4-5 nodes. Red mullet 204 lives mainly at depths of 50 to $100 \mathrm{~m}$., common cuttlefish at depth around 200 $205 \mathrm{~m}$., and European spiny lobster at depths between 20 to $70 \mathrm{~m}$.

206 Although these are the main target species and the most important in terms of 207 abundance, the catches are commonly composed of a very heterogeneous 208 assemblage of species. Finally, in January and February, fishing is not directed 209 at any particular species and the main species caught are usually Scorpaenidae 210 and Serranidae species.

\section{Sampling methods}

213 A pilot study (June-September 2006) was performed to explore the local 214 situation as well to design an appropriate sampling regime. Data were then 215 collected between July 2007 and July 2009 by two observers on board 216 commercial trammel fishing boats.

218 In order to sample the studied fleet as representatively as possible, we aimed 219 to cover all fishing boats and all seasons. However, this was limited by lack of 220 cooperation by some fishermen (who declined to take observers) and weather 221 conditions and, finally, 10 out of 18 trammel fishing boats were sampled.

223 For each fishing operation the observer recorded information on the haul 224 duration, net mesh size, number of $50 \mathrm{~m}$. net panels used, geographical 225 location, latitude and longitude, depth of seabed, moon phase, and the 
226 presence or the absence of evidence of depredation. Evidence of dolphin

227 attacks and depredation was based on the presence of at least one damaged 228 fish in the nets (Lauriano et al. 2004) and/or holes in the nets (Gazo et al. 229 2008).

231 Based on the nature of the damage, the depredation was identified as due to 232 dolphins or other species, such as sea turtles (Caretta caretta, Linnaeus, 1758) 233 or other fish. Fish damage caused by dolphins can be distinguished from 234 damage caused by sea turtles since dolphins bite behind the gills, leaving bite 235 marks with ragged borders and often leaving behind just the head or the body 236 of the fish (Figure 1) whereas sea turtles leave different small bites on the fish 237 (Hernandez-Milian et al. 2008). The fish species caught in the nets were 238 identified, measured and weighed for each haul.

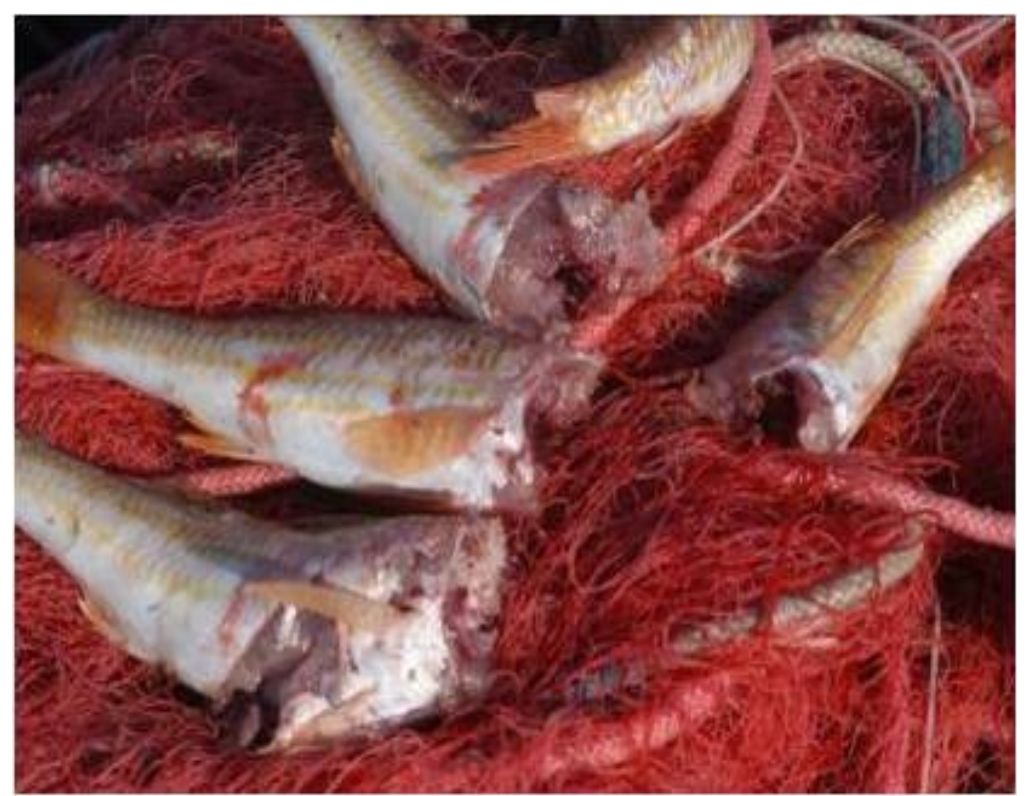

Fig. 1. Photograph of red mullets (M. surmuletus) damaged during a trammel fishing operation. In this photo it is possible see that the heads were severed below the gills, and only the body was left. Note the ragged edges left by the dolphin bites. 
261 In order to identify a more clear definition of the spatial patterns of the fishing 262 effort, the area of interest was divided into five equally sized sub-areas (Figure 263 2).

Fig. 2. Map of the study area, the Archipelago de La Maddalena, Sardinia (Italy), divided into the 5 areas of equal surface area.

281 We concentrated the statistical analysis on the catch of the 7 main species that 282 together represent $90 \%$ of the total catch value. These species are: red mullet 283 (Mullet surmuletus), red scorpionfish (Scorpaena scrofa, Linnaeus, 1758), black 284 scorpionfish (Scorpaena porcus, Linnaeus, 1758), peacock wrasse (Symphodus 285 tinca, Linnaeus, 1758), two-banded seabream (Diplodus vulgaris, Geoffroy 286 Saint-Hilaire, 1817), octopus (Octopus vulgaris, Cuvier, 1797) and common 287 cuttlefish (Sepia officinalis). 
288 Since the catch statistics varied markedly between the boats, we computed the 289 catch per unit effort (CPUE) as the total catch in a fishing operation (in g.), 290 standardized per piece of net (of $50 \mathrm{~m}$.) and per haul duration (in $\mathrm{h}$ ), (CPUE in 291 g. $\left.50 \mathrm{~m}^{-1} \mathrm{~h}^{-1}\right)$. These values were then log transformed to downweight extreme 292 values and to ensure a normal distribution and homoscedasticity.

294 The modelling strategy proposed involves three steps. First we use a Bayesian 295 General Linear Model (GLM) to evaluate which factors influence the CPUE. 296 Secondly, we applied Partial Correspondence Analysis (PCA) to assess which 297 variables affect the variation in species composition of catches. Finally, we 298 implemented a Bayesian logistic regression to determine the extent to which 299 habitat differences contributed to the presence of dolphin interactions.

301 In particular we used a Bayesian approach as it allows both the observed data 302 and model parameters to be considered as random variables, resulting in a 303 more realistic and accurate estimation of uncertainty (Banerjee et al. 2004).

\section{Step 1: Modelling CPUE}

306 The expected values of CPUE in each haul were related to independent variables, namely mesh size, geographical location, moon phase, season, depth of seabed and dolphin interaction factor, according to the general formulation,

$$
\mathrm{CPUE}_{i}=\alpha+X \beta+W_{i}
$$

310 where $X$ is the vector of covariates for each survey $i, \alpha$ is the intercept, $\beta$ is the

311 vector of the model parameters and $W_{i}$ is the spatial random effect. 
313 Except for the variable "depth of seabed", which is continuous, the other

314 explanatory variables are all categorical: mesh size (6", 7", 8", 9", 11", 12"),

315 location (northern, central, western, southern, eastern), moon phase (crescent,

316 full moon, waning, new moon), season (winter, spring, summer, autumn) and

317 dolphin interaction ( $1=$ yes, $0=$ no). Moreover, a random spatial effect

318 (latitude and longitude of the fishing operation) was introduced in the analysis

319 in order to verify the spatial variability of the data within each sub-area.

321 Effects of categorical variables are considered for $k-1$ of the $k$ factor levels, with 322 the remaining one being considered as the base level. Hence the estimated 323 coefficient of each factor level will indicate the deviation with respect to the 324 value of the base level.

326 Once the model has been determined, the next step is to estimate its 327 parameters. Following Bayesian reasoning, the parameters are treated as 328 random variables, and prior knowledge has to be incorporated via the 329 corresponding prior distributions of the said parameters. In particular, for the 330 parameters involved in the fixed effects, we use non-informative Gaussian 331 distributions $\mathrm{N}(0,100)$.

333 A model selection with both backwards and forwards approaches was used to 334 select relevant variables. Specifically, we used the Deviance Information 335 Criterion (DIC), a well-known Bayesian model-choice criterion for comparing 336 complex hierarchical models (Spiegelhalter et al. 2002). Lower values of DIC 337 represent the best compromise between fit and parsimony. 


\section{Step 2: Modelling species composition catches}

340 In order to test the hypothesis that the species assemblage in the catches 341 differs with dolphin depredation, we computed the proportion of each species

342 for both, depredated and non-depredated, fishing operations. Then, we assess 343 whether there was (or not) a real economic loss to fishermen by computing 344 three new categories of economic loss. The species were classified, according 345 to local commercial value per $\mathrm{kg}$., into three different categories: high, medium 346 and low price (Table 1).

Table 1. The seven species that together represent $90 \%$ of the total catches were classified according to their local economic value per $\mathrm{kg}$ (Maddalena fish market) into three different categories: high, medium and low price category.

\begin{tabular}{|l|l|}
\hline \multicolumn{1}{|c|}{ Species } & \multicolumn{1}{c|}{ Category } \\
\hline M.surmuletus & High Price $(15.00-18.00 €)$ \\
\hline S.scrofa & High Price $(14.00-15.00 €)$ \\
\hline O.vulgaris & High Price $(13.00-15.00 €)$ \\
\hline S.tinca & Medium Price $(8.00-9.00 €)$ \\
\hline D.vulgaris & Medium Price $(8.00-9.00 €)$ \\
\hline S.officinalis & Low Price $(5.00-7.00 €)$ \\
\hline S.porcus & Low Price $(5.00 €)$ \\
\hline
\end{tabular}

As data meet normality conditions (Shapiro-Wilk normality test, $p=0.08$ ), we used $Z$-test in order to assess if the differences in the proportions, between depredated and non-depredated fishing operations, were statistically significant.

358 In addition we applied the PCA to assess how much of the variation of the 359 species composition of catches is uniquely explained by dolphin interactions, 360 how much is uniquely explained by environment or how much is explained by 
361 some joint effect of the two components. To partition the total variance of the

362 CPUE of the 7 main species, we ran three different models: a full model with all

363 environmental variables and the dolphin interaction as explanatory variables, a 364 partial model in which environment explains species composition data 365 conditioned on dolphin predation, and a partial model where dolphin interaction 366 explains species composition data conditioned on environment. The 367 significance of each PCA model was tested by Monte Carlo permutations tests, 368 to retain the 10 ones that best explain the variation in the species composition 369 catches. We used as environment variables the depth of the seabed, the 370 season, the moon phase and the geographical location of each fishing 371 operation. For this purpose we used the vegan package of the $R$ software ( $R$ 372 Development Core Team 2014).

\section{Step 3: Modelling dolphin depredation}

375 In addition, in order to assess whether dolphins depredation was related to 376 habitat features, we modelled the occurrence of dolphin depredation using 377 Bayesian logistic regression.

379 The 354 surveys were modelled as a binary process, $Z_{i} \sim$ Binomial $\left(\pi_{i}\right)$, where 1 380 indicates records in which the depredation was recorded, and 0 the opposite. 381 The probability of occurrence of depredation by dolphins is indicated by $\pi_{i}$. The 382 model can be expressed as:

$$
Z_{i} \sim \operatorname{Bin}\left(\pi_{i}\right),
$$

$$
\operatorname{logit}\left(\pi_{i}\right)=\alpha+X \beta+W_{i}
$$

385 where $X_{i}$ is the vector of covariates for each survey $i, \alpha$ is the intercept, $\beta$ is 
386 the vector of regression parameters, $W_{i}$ is the spatial random effect and the 387 relationship between $\pi_{i}$ and the covariates of interest includes the usual logit 388 link. We used as covariates the location, the depth of the seabed, the season, 389 mesh size, the moon phase and a random spatial effect (latitude and 390 longitude). Vague Gaussian distributions for the parameters involved in the 391 fixed effects were used, in order to allow empirically derived distributions. As 392 for the Bayesian GLMs, this model was fitted using both backwards and 393 forwards stepwise procedures and the goodness-of-fit of each model was also 394 assessed using the DIC.

396 To fit Bayesian models we used the integrated nested Laplace approximation 397 (INLA) methodology and software (http://www.r-inla.org). INLA provides 398 accurate approximations to posterior distributions of the parameters and is 399 computationally fast (Rue et al. 2009). In addition, INLA can be used with R 400 software, thus providing a familiar interface for the programming of the model.

\section{RESULTS}

403 Between July 2007 and July 2009 a total of 354 fishery operations was 404 observed and evidence of dolphin predation was recorded in 84 of these cases. 405 In particular, 54 out 354 fishing operations were sampled in the Western area, 40684 in the Central, 78 in the Northern, 74 in the Eastern and 64 in the Southern 407 area.

408

409 Relationship between dolphin interactions and total CPUE

410 The Bayesian model of CPUE selected for its best fit (based on the lowest DIC) 
411 includes season, moon phase, mesh size, depth of seabed and dolphin

412 interaction as covariates.

413

414 Table 2 presents a numerical summary of the posterior distributions of the fixed

415 effects for this final model.

416

417 Table 2. Numerical summary of the posterior distributions of the fixed effects for the 418 best CPUE model. This summary contains the posterior mean of the estimated 419 paramters, the standard deviation, the median and a 95\% credible interval, which is a 420 central interval containing 95\% of the probability under the posterior distribution. 421 Effects of categorical variables are considered for $k-1$ of the $k$ factor levels, with the 422 remaining one being considered as the base level. Hence the estimated posterior 423 mean of each factor level will indicate the deviation with respect to the value of the 424 base level.

425

426

\begin{tabular}{|c|c|c|c|c|}
\hline Variable & Mean & Sd & $\mathbf{Q}_{0.25}$ & $\mathbf{Q}_{0.95}$ \\
\hline Intercept & -1.07 & 0.90 & -2.85 & 0.71 \\
\hline Season(Summer) & 1.49 & 0.36 & 0.78 & 2.21 \\
\hline Season(Winter) & 1.80 & 0.46 & 0.89 & 2.72 \\
\hline Season(Spring) & 0.93 & 0.26 & 0.42 & 1.44 \\
\hline Moon(Crescent) & 1.07 & 0.26 & 0.55 & 1.58 \\
\hline Moon(New) & 0.32 & 0.32 & -0.31 & 0.94 \\
\hline Moon(Waning) & 0.47 & 0.25 & -0.03 & 0.96 \\
\hline Dolphin interaction(Yes) & -0.43 & 0.26 & -0.94 & 0.07 \\
\hline Mesh size(7”) & 4.71 & 0.73 & 3.27 & 6.16 \\
\hline Mesh size(8”) & 4.64 & 0.81 & 3.05 & 6.24 \\
\hline Mesh size(9”) & 4.27 & 0.72 & 2.85 & 5.68 \\
\hline Mesh size(11”) & 5.45 & 0.78 & 3.91 & 6.99 \\
\hline Mesh size(12”) & 6.19 & 0.75 & 4.72 & 7.66 \\
\hline Depth of seabed & -0.03 & 0.01 & -0.04 & 0.01 \\
\hline
\end{tabular}

428 Results showed that winter is the season with the highest estimated CPUE

429 (posterior mean $=1.80 ; 95 \% \mathrm{Cl}=[0.89,2.72]$ ) with respect to the reference 430 level (autumn season). Summer and spring seasons also showed higher 431 estimated CPUE than the reference level (respectively, posterior mean $=1.49$; $43295 \% \mathrm{Cl}=[0.78,2.21]$ and posterior mean $=0.93 ; 95 \% \mathrm{Cl}=[0.42,1.44])$, 
433 leaving autumn as the season with the lowest estimated CPUE.

434

435 The crescent moon is the phase that shows the highest estimated CPUE 436 (posterior mean $=1.07 ; 95 \% \mathrm{Cl}=[0.55,1.58]$ ) with respect to the reference 437 level (full moon), which is the phase that presents the lowest estimated CPUE. 438

439 Dolphin interaction was associated with a lower estimated CPUE than the 440 reference level (No dolphin interaction) (posterior mean $-0.43 ; 95 \% \mathrm{Cl}=[-0.94$, $4410.07])$.

443 Using 6" mesh size as the reference level, all other mesh sizes show higher 444 CPUEs. Table 2 shows a trend for greater mesh size to correspond to higher 445 estimated CPUE.

447 Finally, the seabed depth shows a negative relationship with estimated CPUE 448 (posterior mean of slope coefficient $-0.03 ; 95 \% \mathrm{Cl}=[-0.04,0.01]$ ), i.e. catch 449 rates were high in shallower water.

450

\section{The species composition of catches}

452 In nets not attacked by dolphins the most common species caught was the red 453 mullet (31\% of total CPUE), followed by octopus (18\%), cuttlefish and red 454 scorpionfish (14\% each), black scorpionfish (7\%), peacock wrasse (4\%) and 455 two-banded seabream (2\%). The remaining $10 \%$ of the total CPUE was 456 composed of various species belonging for the most part to the Serranidae 457 family (Figure 3). 


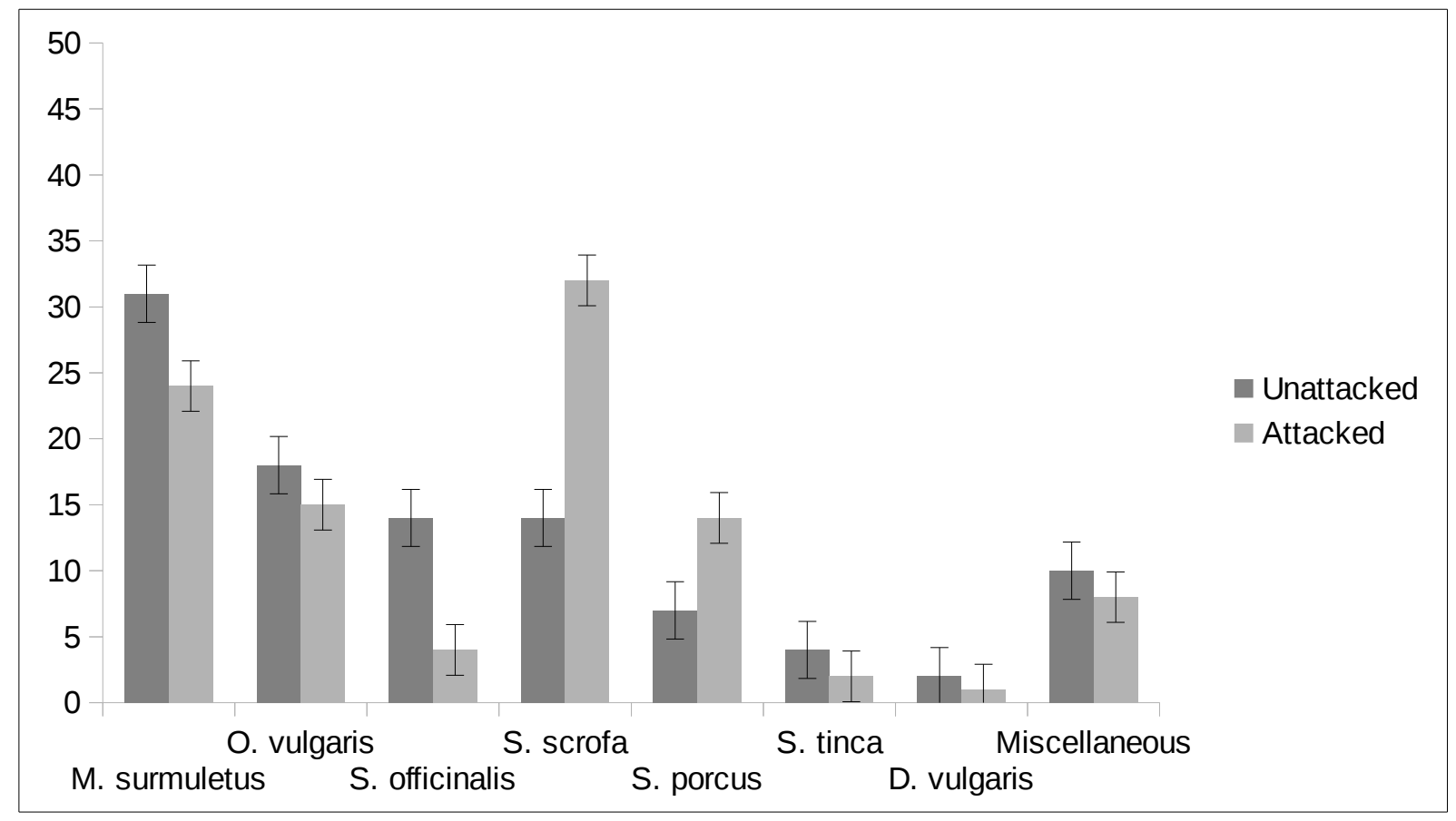

459 Fig. 3. Percentages of the seven main species fished in relation to total CPUE, with 460 and without depredation by dolphins. The class "Miscellaneous" includes several 461 species belonging to the Serranidae family. Error bars represent the standard 462 deviation.

464 When dolphin interaction was recorded, the species composition of catch was 465 different from when dolphins were absent. The species that showed the 466 greatest reduction in catch were the cuttlefish $(-10 \% ; z=3.33 ; p<0.05)$ 467 followed by red mullet $(-7 \% ; z=1.11 ; p>0.05)$, while the greatest increases 468 were seen for the two species of scorpionfish, with catch of the red scorpionfish 469 up by $18 \%(z=-3.06 ; p<0.05)$, and the black scorpionfish by $7 \%(z=-0.166$; $470 p<0.05)$.

472 In the presence of dolphin interactions, red scorpionfish became the most 473 important species, comprising around 32\% ( $z=-3.06 ; p<0.05)$ of the total 474 CPUE, and black scorpionfish rose to $14 \%(z=-0.166 ; p<0.05)$ of the CPUE. 475 Red mullet was reduced to $24 \%(z=1.11 ; p>0.05)$ of total CPUE and the 
476 catches of octopus and two-banded seabream fell to $15 \%(z=0.6 ; p>0.05)$

477 and $1 \%(z=0.08 ; p>0.05)$, respectively. Catches of cuttlefish and peacock

478 wrasse also declined, to $4 \%(z=3.33 ; p<0.05)$ and $2 \%(z=5 ; p<0.05)$,

479 respectively (Figure 3$)$. Miscellaneous species fell to $8 \%(z=0.51 ; p>0.05)$ of 480 total CPUE.

481

482 High price category (red mullet, red scorpionfish and octopus) species were $8 \%$ 483 more abundant in catches associated with dolphin depredation $(z=-1.21 ; p<$ 4840.05 , Figure 4).

485

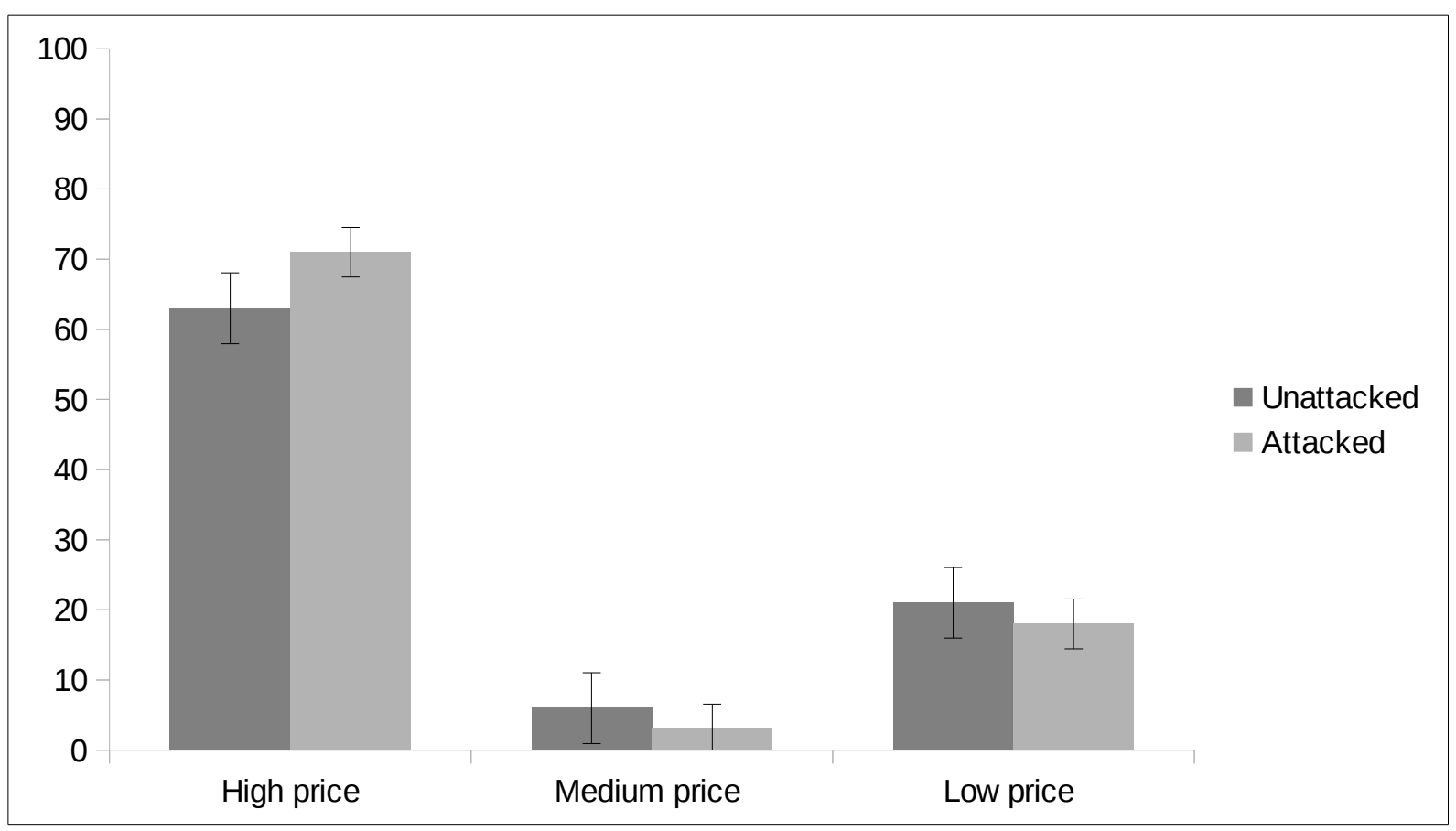

487 Fig. 4. Percentages of the CPUE (in $g .50 \mathrm{~m}^{-1} \mathrm{~h}^{-1}$ ) in three price categories, by species, 488 in nets unattacked and attacked by bottlenose dolphins. Error bars represent the 489 standard deviation.

490

491 The lower amounts of red mullet and octopus in catches attacked by dolphins 492 were offset in terms of economic value by the higher amount of red 
493 scorpionfish. The yields of both the medium (two-banded seabream and 494 peacock wrasse) and low (cuttlefish and black scorpionfish) price categories 495 were about $3 \%$ for low price) lower in catches that suffered dolphin attacks, 496 differences which were not statistically significant $(z=1.07 ; p>0.05$ and $z=$ $497 \quad 0.6 ; p>0.05$. respectively).

498

499 The analysis of the species composition of catches through the PCA shows that 500 the total percentage of variance explained by the environmental variables and 501 dolphin interactions is equal $25.52 \%$. In particular, for the "environmental" PCA 502 of the species assemblages, controlling for the dolphin interaction, the 503 percentage of variance explained is equal to $17.75 \%$. For this PCA, the Monte 504 Carlo tests of the relationships found $(F=1.88, P<0.05)$ were significant, 505 indicating that environment variables explain a significant proportion of 506 variation in species assemblage compositions after excluding effects of dolphin 507 interaction. On the contrary, for the "dolphin interaction" PCA, the variance 508 explained is about $4.25 \%$ and the Monte Carlo tests of the relationships found $509(\mathrm{~F}=4.06, \mathrm{P}<0.05)$ were significant, indicating that dolphin interaction also 510 explained a significant part of the variation in the composition of species 511 assemblages after taking account of effects of environmental variables.

\section{Logistic regression for dolphin depredation}

514 The selected model for the depredation probability included as final relevant 515 predictors the location, season and depth of seabed (Table 3). 
541 Depth of the seabed shows a negative relationship with the occurrence of

Table 3. Numerical summary of the posterior distributions of the fixed effects for the best binomial model (dolphin depredation). This summary contains the posterior mean of the estimated parameters, the standard deviation, the median and a 95\% credible interval, which is a central interval containing $95 \%$ of the probability under the posterior distribution. Effects of categorical variables are considered for $k-1$ of the $k$ factor levels, with the remaining one being considered as the base level. Hence the estimated posterior mean of each factor level will indicate the deviation with respect to the value of the base level.

\begin{tabular}{|c|c|c|c|c|}
\hline Variable & Mean & Sd & $\mathbf{Q}_{\mathbf{0 . 2 5}}$ & $\mathbf{Q}_{\mathbf{0 . 9 5}}$ \\
\hline Intercept & 0.45 & 0.98 & -1.46 & 2.42 \\
\hline Season(Summer) & -3.20 & 0.66 & -3.88 & 1.21 \\
\hline Season(Winter) & 2.41 & 0.24 & -0.89 & 2.72 \\
\hline Season(Spring) & -2.71 & 0.46 & -1.42 & 3.44 \\
\hline Area(Southern) & -1.62 & 0.72 & -3.09 & 0.25 \\
\hline Area(Eastern) & -0.32 & 0.88 & -2.20 & 1.28 \\
\hline Area(Central) & 2.16 & 0.64 & 0.93 & 3.48 \\
\hline Area(Western) & -0.22 & 0.58 & -1.20 & 1.48 \\
\hline Depth of seabed & -0.05 & 0.02 & -0.11 & -0.00 \\
\hline
\end{tabular}

There was an apparent seasonal effect, with depredation more frequent in the winter season. Indeed, the winter shows the highest estimated probability of depredation (posterior mean $=2.41 ; 95 \% \mathrm{Cl}=[-0.89,2.72]$ ) with respect to the reference level (autumn season). Conversely, the summer showed the lowest estimated probability of depredation compared the reference level (posterior mean $=-3.20 ; 95 \% \mathrm{Cl}=[-3.88,1.21])$.

The central area is the zone that shows the highest dolphin interaction (posterior mean $=2.16 ; 95 \% \mathrm{Cl}=[0.93,3.48]$ ) with respect to the reference level (northern area), while the southern is the area with the lowest estimated probability of depredation (posterior mean $=1.62 ; 95 \% \mathrm{Cl}=[-3.09,0.25]$ ). 
542 dolphin interaction (posterior mean slope coefficient $-0.05 ; 95 \% \mathrm{Cl}=[-0.11$,

$543-0.00]) ;$ i.e. there were more dolphin interactions in shallower water.

544

\section{DISCUSSION}

546 In the Archipelago de La Maddalena, fishing operations during which no

547 interactions with dolphins were recorded showed both quantitative and

548 qualitative differences in catch composition compared with those for which

549 attacks were reported. Dolphin attacks were also associated with lower values

550 of CPUE. Lauriano et al. (2004) found a similar trend in Asinara (NW Sardinia)

551 and the authors suggested that this could be due either to dolphins eating fish

552 from the nets, reducing the CPUE, or dolphins scaring fish away from the nets

553 so fewer are caught. However, it is also possible (albeit less plausible) that

554 dolphin prefer the areas where the fish abundance is lower or that they are

555 associated with other predators which eat the catches (Torres 2007).

556

557 It is worth mentioning that, in the waters of the Archipelago de La Maddalena,

558 large fish (>3 m), sharks and sea turtles are extremely rare in inshore waters

559 where fishing is concentrated. An incidence of predation by sea turtles of only

$5601 \%$ was recorded during the 354 fishing operations examined. However, in

561 addition to the presence or absence of dolphin interactions, there are other

562 factors that contributed significantly to the variability of CPUE, such as depth of

563 seabed, location, season and moon phase. Moreover, the presence of dolphin

564 interactions could also be predicted from environmental conditions, suggesting

565 that the link between dolphin interactions and catch is not simply one of cause

566 and effect. Equally, however, the dolphin-environmental relationship may be 
564 indirect. For example, fish catches may depend on environmental conditions,

565 dolphin depredation depends on fish catch and therefore dolphin depredation

566 will appear to depend on the environment.

568 Some other studies have found a positive association between dolphin 569 predation and high CPUE. Silva et al. (2002), in the Azores, and Rocklin et al. 570 (2009), in Corsica, reported that catches were higher in the presence of

571 dolphins. This could be explained by the fact that dolphins only attack the nets 572 in which the catches are high, or that they drive the fish into nets, thus 573 increasing the catches of fish and CPUE, or simply that dolphins tend to be

574 found where fish abundance is higher.

576 In the present study, the spatial component appears to be an important factor 577 only for the probability of occurrence of dolphin interaction. Indeed, Bayesian 578 logistic regression showed that the central area is the one with highest 579 probability of occurrence of dolphin interaction. Geographical variation in the 580 effect of dolphin interactions probably depends on the extent to which dolphins 581 and fisheries overlap in space and time when exploiting their shared resource 582 (Brotons et al. 2008; Matthiopoulos et al. 2008). A possible counter-argument is 583 that dolphins and fishers both target the best habitat so that, based on fish 584 abundance, CPUE should be higher in dolphin areas than in non-dolphin areas 585 and the loss due to dolphins could thus be bigger than it seems.

587 There was also seasonal variation in quantitative catch composition. Our 588 results are consistent with those obtained by Brotons et al. (2008) in the 
589 Balearic Islands. The winter season is the period with the highest CPUE and the 590 highest occurrence of dolphin interaction. There are different possible reasons 591 for the observed seasonal variation in depredation frequency, including 592 seasonal movement by dolphins (ongoing studies of the dolphin population in 593 the area suggest that dolphins have an inshore distribution during winter, (see 594 http://www.lamaddalenapark.it for more details)). The increased nautical traffic 595 in summer that characterizes this area could prompt displacement of these 596 animals to areas where there are fewer recreational boats, to avoid noise and 597 the risk of collisions. Gonzalvo et al. (2008) found a similar migration trend 598 around Balearic Islands. In the Archipelago de La Maddalena, as in the Balearic 599 Islands, tourism is the main industry, with around 8.5 million visitors each year 600 and around 15,000 registered leisure boats (Rotta 2009). Seasonal movements 601 by dolphins may reduce the probability that dolphins encounter trammel nets 602 during summer and can therefore lead to higher rates of depredation in winter.

604 CPUE was also influenced by the moon phase. The highest estimated CPUE 605 values were recorded during the crescent moon phase. Although it is known 606 that the lunar cycle affects the catchability of many species, few studies have 607 been carried out to test this hypothesis in the Mediterranean Sea. Yousif \& 608 Sabrah (2004) showed significantly higher CPUE for mullet species (Upeneus 609 spp.) at full moon in the Red Sea. More information is known about the 610 influence of moon phase on the migration of top predators (Neves Dos Santos 611 \& Garcia 2005; Damalas et al. 2007). Hernandez-Milian et al. (2008) showed 612 significant positive relationships between moon phase and sightings of short613 beaked common dolphin (Delphinus delphis, Linnaeus, 1758) and Atlantic 
614 spotted dolphin (Stenella frontalis, Cuvier, 1829) in the Azores. Although

615 previous studies suggest that moon phase is likely to be important in

616 determining behavior of the many delphinid species that forage on vertically

617 migrating prey (Hernandez-Milian et al. 2008; Benoit-Bird et al. 2009), our

618 results show that the lunar phase is not correlated with dolphin interaction in

619 these waters.

620

621 Trammel nets of 12 nodes mesh size showed the highest CPUEs among gears

622 used by fishermen in this study. This type of net is used for targeting red

623 mullet, which is one the most frequently caught species in the area. The mesh

624 size seems to have no effect on the occurrence of the dolphin interaction.

626 Several studies have shown that the bathymetry of an area can be a significant 627 factor in determining the distribution of dolphins, depth being one of the 628 variables with the strongest influence (e.g. Cañadas et al. 2002; Yen et al. 629 2004). Results of this study show a clear negative correlation between 630 occurrence of dolphin interaction and depth of seabed. In addition Bayesian 631 analysis show that CPUE was negatively correlated with the depth of seabed, 632 which is probably related to the habitat of the target species of the fisheries, 633 which usually inhabit shallow waters (Blanco et al. 2001). It is well known that 634 recruitment for most of the fish species in the Mediterranean Sea, takes place 635 in shallow water near the coast (depth $<60 \mathrm{~m}$ ), where the trammel nets are 636 sited (Lleonart \& Maynou 2003). A likely explanation is that fish distribution is 637 strongly affected by depth and consequently the predator distribution is also 638 related to depth (Massutí \& Reñones 2005). 
640 The results of our study concerning species depredated by bottlenose dolphins

641 show similarity to those obtained by Lauriano \& Di Muccio (2002) in Sardinia 642 and Rocklin et al. (2009) in Corsica (close to Archipelago de La Maddalena), 643 both studies on trammel nets. In these cases, red mullet was the most 644 depredated species, followed by comber (Serranus cabrilla, Linnaeus, 1758) 645 and forkbeard (Phycis phycis, Linnaeus, 1766) and no evidence of depredation 646 on cephalopods was recorded.

648 In the Balearic Islands, Brotons et al. (2008) observed high CPUE of octopus 649 when dolphins were present. The authors suggest that octopuses are attracted 650 to depredated nets by odours released from damaged fish after depredation. In 651 our study cuttlefish is the species most depredated by dolphins, followed by 652 red mullet and octopus. It is known that cephalopods are part of the bottlenose 653 dolphin diet, and similar patterns have been found in different Mediterranean 654 Sea areas (Blanco et al., 2001).

656 Scorpionfish species catches were higher in the presence of dolphins in the 657 fishing area. Similar results have been demonstrated in Corsican waters 658 (Rocklin et al. 2009), where the occurrence of bentho-pelagic fish was higher in 659 the presence of dolphins, balanced by a correspondingly lower occurrence of 660 the reef associated fish group. The authors suggested that fish located in the 661 water column, such as bentho-pelagic fish, may try to escape from dolphins, 662 increasing their risk of being caught in the nets, whereas reef-associated fish 663 remained hidden in rocks. Little is known about the general behaviour of fish 
664 facing a predator, but it seems reasonable to propose that demersal species, 665 such as the scorpionfish species, show similar behaviour to bentho-pelagic 666 species in the Corsica waters. Obviously another explanation could be that 667 dolphins are present in the areas where the occurrence of the red scorpionfish 668 is higher, independently of their foraging behaviour.

670 In this study, we cannot argue that dolphins deliberately drive fish into the nets

671 to facilitate their depredation, or say whether dolphin attacks generate panic 672 movements among fish schools. Camera and acoustic detection-based studies 673 of nets would be needed to discover how the interaction works. However, the 674 PCA results suggest that it is more likely that these differences in species 675 composition are due to habitat effects or a mixture of difference of habitats and 676 dolphin-induced effects.

678 In economic terms, the difference in species composition in the event of 679 dolphin depredation (regardless of whether it is directly caused by the dolphin 680 depredation) does not significantly alter the profitability of catches for 681 fishermen. Indeed, high price category (red mullet, red scorpionfish and 682 octopus) species were $8 \%$ more abundant in catches associated with dolphin 683 interaction. The lower amounts of red mullet and octopus in the total catch 684 were offset in terms of economic value by the higher amount of red 685 scorpionfish.

687 It should be noted that other economic losses have not been evaluated in this 688 study. As mentioned in the introduction, interaction of dolphins often causes 
689 damage to the nets, e.g. holes (Fertl \& Leatherwood 1997; Brotons et al. 2008), 690 reducing catching efficiency and capacity (Bearzi 2002), and resulting in lost 691 time and direct financial losses by fishermen (Zahri et al. 2004). Unfortunately, 692 we don't have any additional information about these others factors that could 693 help to assess these economic losses in the area.

695 Potentially the most worrying finding was the high probability of interactions 696 with dolphins observed around the Archipelago de La Maddalena waters, which 697 reached $24 \%$ per fishing operations. This value is much higher than that 698 observed by Lauriano et al. (2004) in Asinara (10\%) and the $12.5 \%$ recorded by 699 Rocklin et al. (2009) in Corsica, both on trammel net fisheries. Possible explanations for this localized effect include locally depleted fish stocks or an 701 increase in the number of animals specializing on depredating nets in this area. 702 Indeed, Pennino et al. (2013) provides evidence for socially learned tradition in 703 foraging tactics within a community of resident wild bottlenose dolphins in 704 these waters.

706 This study allows better understanding of how coastal bottlenose dolphins 707 interfere with the trammel fishery in the Archipelago de La Maddalena. The 708 nature and level of interactions will be dependent on several factors. For 709 example, in this study different environmental factors were found to be 710 correlated with low fish catches (e.g. season, depth of seabed, area). 711 Nevertheless, fishermen perceived that only dolphins were detrimental to their 712 activities. 
714 Considerable flexibility of approach in mitigating and managing this issue will

715 be required in this area. Based on our analyses of factors affecting CPUE and

716 the incidence of depredation, it is possible that changes in fishing practices, in

717 relation to the fishing grounds or fishing patterns could result in both increased

718 CPUE and decreased depredation. Possible tools for an efficient fisheries

719 management could be spatial and temporal closures of high-intensity dolphin

720 interaction areas. However, in order to identify and locate these potential

721 spatio-temporal closures, a more solid knowledge of species-environment

722 relationships is needed, as well as more detailed information about the fishing

723 effort in this area.

725 Alternatively, an agreed mechanism to estimate economic costs could be

726 established between fishermen and National Park Authority, which could

727 support a compensation scheme for predator damage, in exchange for greater

728 collaboration in research by fishermen. This approach has been tested by the

729 Swedish

Environmental

Protection

Agency

730 (http://www.internat.naturvardsverket.se/), which provides a reimbursement for

731 damage caused by dolphins. Reimbursement requires that fishermen give the

732 net to the coastguard who must verify the extent of the damage. This practice

733 interrupts fishing activities, and is inconvenient for fishermen who wish to

734 apply (Lauriano et al. 2004). However it is necessary that these

735 reimbursements are targeted and actively controlled, otherwise adverse effects

736 may be obtained as in the Archipelago of Madeira, where damage to gear

737 caused by monk seals (Monachus monachus, Hermann, 1779) is reported to be

738 overestimated by fishermen seeking for economic compensation (Hale et al. 
741 Despite strong evidence that dolphin depredation occurs, it appears to lead to

742 minimal loss of revenue obtained from the catch and, if other economic

743 impacts (e.g. net damage) prove not to be a major issue, management action

744 could therefore include educating fishers to accept the interactions.

745 Another possibility is the use of acoustic deterrents to discourage dolphins from 746 approaching nets, although raises a range of other issues, including the 747 possibility of fish being deterred from entering the nets, the possibility of 748 causing hearing damage in the dolphins, and the cost of purchasing and 749 maintaining such devices.

751 Future studies are needed in order to fill knowledge gaps regarding this historic 752 conflict and to understand what might be the best option to mitigate this 753 problem. Further and more specific research should be conducted to determine 754 the economic losses suffered by fishermen, taking into account damaged gear 755 and lost fishing time. In addition, will be useful to collect information about 756 dolphins by-cacth in this area, as by-cacth also damages fishing gear so is part 757 of the economic evaluation. Furthmore, knowledge about dolphins by-cacth is 758 essential for conservation programs because it provides a clear picture of the 759 relationship between fisheries and dolphins.

760 More detailed studies are needed on the spatio-temporal distribution of fishing 761 activity, on distribution, habitat use and movements of bottlenose dolphins, as 762 well as in situ data on the nature of the interaction between dolphins, fish and 763 net. For example, are dolphins usually present in the area at the time the net is 
764 set, does their presence affect fish behavior and how often are fish completely

765 removed by dolphins? A combination of underwater cameras adjacent to nets,

766 coupled with acoustic detection of dolphins could help answer these questions.

768 ACKNOWLEDGEMENTS

769 This study was part of the "Tursiops Project" of the Dolphin Research Centre of 770 Caprera, La Maddalena. Financial and logistic support was provided by the 771 Centro Turistico Studentesco and by the National Park of the Archipelago di La 772 Maddalena. Our thanks go also to the numerous volunteers of the Caprera 773 Dolphin Reasearch Center and especially to Marco Ferraro and Mirko Ugo, 774 whose assistance during field observation and skills as a boat driver were 775 invaluable.

\section{REFERENCES}

778 Banerjee, S., Carlin, B., Gelfand, A., 2004. Hierarchical Modeling and Analysis 779 for Spatial Data. Chapman and Hall/CRC Press.

780 Barone, G. 1895. Modificazioni delle abitudini del delfino comune (Delphinus 781 delphis) osservate in Liguria e prodotte dal generalizzarsi della pesca intensiva. 782 Neptunia 10, $156-164$.

783 Bearzi, G. 2002. Interactions between cetaceans and fisheries: Mediterranean 784 Sea. Pages 78-97 in G. Notarbartolo di Sciara, ed. Cetaceans inthe 785 Mediterannean and Black Seas: state of knowledge and conservation 786 strategies. Monaco: A report to the ACCOBAMS Secretariat.

787 Benoit-Bird, K.J., A.D. Dahoodm \& D. Würsig. 2009. Using active acoustics to 788 compare lunar effects on predator-prey behavior in two marine mammal 
species. Marine Ecology Progress Series 395: 119-135.

790 Blanco, C., O. Salomon \& J.A. Raga. 2001. Diet of the bottlenose dolphin

791 (Tursiops truncatus) in the western Mediterranean Sea. Journal of the Marine

792 Biological Association of the United Kingdom 81:1053-1058.

793 Brotons, J.M., A.M. Grau \& L. Rendell. 2008. Estimating the impact of 794 interactions between bottlenose dolphins and artisanal fisheries around the 795 Balearic Islands. Marine Mammal Science 24:112-127.

796 Busnel, R.G. 1973. Symbiotic relationship between man and dolphins. 797 Transactions of the New York Academy of Sciences 35:112-131.

798 Cañadas, A., R. Sagarminaga \& S. García-Tiscar. 2002. Cetacean distribution 799 related with depth and slope in the Mediterranean waters off southern Spain. 800 Deep Sea Research Part 1 Oceanographic Research Paper 49 (11):2053-2073.

801 Chilvers, B.L. \& P.J. Corkeron. 2001. Trawling and bottlenose dolphins' social 802 structure. Proceedings of the Royal Society of London B Biological Sciences $803 \quad 268: 1901-1905$.

804 Conides, A. \& C. Papaconstantinou. 2001. The basis of coastal fishery 805 management for small fishing communities: the case of the shrimp Penaeus 806 kerathurus fishery in western Greece. Naše more, Journal of marine science and 807 technology 48: 231-236.

808 Corkeron, P.J., M.M. Bryden \& K.E. Hedstrom. 1990. Feeding by bottlenose 809 dolphins in association with trawling operations in Moreton Bay, Australia. 810 Pages 329-336 in S. Leatherwood and R. R. Reeves, eds. The bottlenose 811 dolphin. Academy Press, San Diego, CA.

812 Cox, T.M., A.J. Read, D. Swanner, K. Urian \& D. Waples. 2003. Behavioral 813 responses of bottlenose dolphins, Tursiops truncatus, to gillnets and acoustic 
814 alarms. Biological Conservation 115:203-212.

815 Damalas, D., P. Megalofonou \& M. Apostolopoulou. 2007. Environmental, 816 spatial, temporal and operational effects on swordfish (Xiphias gladius) catch

817 rates of eastern Mediterranean Sea Iongline fisheries. Fisheries Research 84: $818 \quad 233-246$.

819 Díaz-López, B. 2006. Interactions between Mediterranean bottlenose dolphins 820 (Tursiops truncatus) and gillnets off Sardinia, Italy. ICES Journal of Marine 821 Science 63:946-951.

822 Esposito, A., G. Meo \& E. Salusti. 1992. A Numerical barotropic model of marine 823 currents in the Archipelago of La Maddalena. II Nuovo Cimento 3:273-285.

824 Estes, J.A., M.T. Tinker, T.M. Williams \& D.F. Doak. 1998. Killer whale predation 825 linking oceanic and nearshore ecosystems. Science 282:473-476.

826 Fertl, D. \& S. Leatherwood. 1997. Cetacean interactions with trawls: A 827 preliminary review. Journal of Northwest Atlantic Fishery Science 22:219-248.

828 Gazo, M., J. Gonzalvo \& A. Aguilar. 2008. Pingers as deterrents of bottlenose 829 dolphins interacting with trammel nets. Fisheries Research 92:70-75.

830 Gönener, S. \& S. Özdemir. 2012. Investigation of the Interaction Between 831 Bottom Gillnet Fishery (Sinop, Black Sea) and Bottlenose Dolphins (Tursiops 832 truncatus) in Terms of Economy. Turkish Journal of Fishery Aquatic Science 12: $833 \quad 115-126$.

834 Gonzalvo, J., M. Valls, L. Cardona \& A. Aguilar. 2008. Factors determining the 835 interaction between common bottlenose dolphins and bottom trawlers off the 836 Balearic Archipelago (western Mediterranean Sea). Journal of Experimental 837 Marine Biological Ecology 367:47-52.

838 Gorzelany, J.F. 1998. Unusual deaths of two free-ranging Atlantic bottlenose 
839 dolphins (Tursiops truncatus) related to ingestion of recreational fishing gear.

840 Marine Mammal Science 14:614-617.

841 Hale, R., R. Pires, P. Santos \& A.A. Karamanlidis. 2011. Mediterranean Monk Seal

842 (Monachus monachus): Fishery Interactions in the Archipelago of Madeira.

843 Aquatic Mammals 37(3):298-305.

844 Hamre, J. 2003. Capelin and herring as key species for the yield of Northeast

845 Arctic cod. Results from multispecies model runs. Scientia Marina 67:315-323.

846 Haug, T., U. Lindstrøm and K.T. Nilssen. 2002. Variations in minke whale

847 (Balaenoptera acutorostrata) diet and body condition in response to ecosystem 848 changes in the Barents Sea. Sarsia 87:409-422.

849 Hernandez-Milian, G., S. Goetz, C. Varela-Dopico, J. Rodriguez-Gutierrez, et al. 850 2008. Results of a short study of interactions of cetaceans and longline 851 fisheries in Atlantic waters: environmental correlates of catches and 852 depredation events. Hydrobiolgia 612:25 -268.

853 Jackson, J.B., M.X. Kirby, W.H. Berger, K. A. Bjorndal, L.W. Botsford, B.J. Bourque

$854 \&$ R.H. Bradbury. 2001. Historical overfishing and the recent collapse of coastal 855 ecosystems. Science 293:629-638.

856 Lauriano, G. \& S. Di Muccio. 2002. Check list of fish damage caught in bottom 857 trammel nets in the Asinara Island National Park (north western Sardinia). 858 Biolgia Marina Mediterranea 9:679-682.

859 Lauriano, G., C.M. Fortuna, G. Moltedo \& G. Notarbartolo di Sciara. 2004. 860 Interactions between common bottlenose dolphins (Tursiops truncatus) and the 861 artisanal fishery in Asinara Island National Park (Sardinia): assessment of catch 862 damage and economic loss. Journal of Cetacean Research and Management 6: $863 \quad 165-173$. 
864 Lauriano, G., L. Caramanna, M. Scarno \& A. Andaloro. 2009. An overview of 865 dolphin predation in Italian artisanal fisheries. Journal of Marine Biological 866 Association of the United Kingdom 89: 921-929.

867 Lleonart, J. \& F. Maynou. 2003. Fish stock assessments in the Mediterranean 868 state of the art. Scientia Marina 67:37-49.

869 Massutí, E. \& O. Reñones. 2005. Demersal resource assemblages in the trawl 870 fishing grounds off the Balearic Islands (western Mediterranean). Scientia 871 Marina 69(1):167-181.

872 Matthiopoulos, J., S. Smout, A.J. Winship, D. Thompson, I.L. Boyd \& J. Harwood. 873 2008. Getting beneath the surface of marine mammal-fisheries competition. 874 Mammal Review 38:167-188.

875 Mcmahon, C.R., M.N. Bester, R.B. Burton, M.A. Hindell \& C.J.A. Bradshaw. 2005. 876 Population status, trends and a re-examination of the hypotheses explaining 877 the recent declines of the southern elephant seal Mirounga leonine. Mammal 878 Review 35(1):82-100.

879 Merrick, R.L., M. Kathryn Chumbley \& G. Vernon Byrd. 2011. Diet diversity of 880 Steller sea lions (Eumetopias jubatus) and their population decline in Alaska: a 881 potential relationship. Canadian Journal of Fisheries and Aquatic Science 54(6): $882 \quad 1342-1348$.

883 Milette, L.L. \& A.W. Trites. 2003. Maternal attendance patterns of Steller sea 884 lions (Eumetopias jubatus) from stable and declining populations in Alaska. 885 Canadian Journal of Zoology 81:340-348.

886 Naceur, L.B., A. Gannier, M.N. Bradai, et al. 2004. Recensement du grand 887 dauphin Tursiops truncatus dans les eaux tunisiennes. Bulletin de I'Institut 888 National Scientifique et Technique de la Mer de Salammbó 31:75-81. 
889 Neil, D.T. 2002. Cooperative fishing interactions between Aboriginal Australians 890 and dolphins in eastern Australia. Anthrozoos 15:3 -18.

891 Neves Dos Santos, M. \& A. Garcia. 2005.The influence of the moon phase on 892 the CPUEs for the Portuguese swordfish (Xiphias gladius L., 1758) fishery. 893 Collective Volume of Scientific Papers ICCAT 58(4):1466-1469.

894 Notarbartolo di Sciara G., T. Agardy, D. Hyrenbach, T. Scovazzi \& P. van 895 Klaveren. 2008. The Pelagos Sanctuary for Mediterranean marine mammals. 896 Aquatic Conservation 18:367-391.

897 Northridge, S. 1984. World review of interactions between marine mammals 898 and fisheries. FAO Fisheries Technical Paper no 251. Food and Agriculture 899 Organization, Rome, 190 pp.

900 Ormerod, S.J. 2003. Current issues with fish and fisheries: editor's overview and 901 introduction. Journal of Applied Ecology 40: 204-213.

902 Pennino M.G., M. Mendoza, A. Pira, A. Floris \& A. Rotta. 2013. Assessing 903 Foraging Tradition in Wild Bottlenose Dolphins (Tursiops truncatus). Aquatic 904 Mammals, 39(3): 282-289.

905 Pryor K., J. Lindbergh, S. Lindbergh \& R. Milano. 1990. A dolphin-human fishing 906 cooperative in Brazil. Marine Mammal Science 6:77-82.

907 R Development Core Team 2014. R: A language and environment for statistical 908 computing.

909 Reeves, R.R., A.J. Read \& G. Notarbartolo di Sciara. 2001. Report of the 910 workshop on interactions between dolphins and fisheries in the Mediterranean:

911 evaluation of mitigation alternatives. Report of ICRAM, Rome, Italy. 44 pp.

912 Rocklin, D., M.C. Santoni, J.M. Culioli, J.A. Tomasini, D. Pelletir \& D. Mouillot 913 2009. Changes in the catch composition of artisanal fisheries attributable to 
914 dolphin predation in a Mediterranean marine reserve. ICES Journal of Marine

915 Science 66:699-707.

916 Rotta, A. 2009. Stato di benessere delle popolazioni di cetacei e marangone dal

917 ciuffo nel nord Sardegna. PhD thesis. University of Sassari, Sardinia, Italy.

918 Rue, H., S. Martino \& N. Chopin. 2009. Approximate Bayesian inference for 919 latent Gaussian models by using integrated nested Laplace approximations. 920 Journal of the Royal Statistical Society, Series B 71(2):319-392.

921 Silva, M.A., R. Feio, R. Prieto, J.M. Goncalves \& R.S. Santos. 2002. Interactions 922 between cetaceans and the tuna fishery in the Azores. Marine Mammal Science 923 18:893-901.

924 Spiegelhalter, D., N. Best, B. Carlin \& A. van der Linde. 2002. Bayesian 925 measures of model complexity and fit. Journal of the Royal Statistical Society, 926 Series B 64:583 -616.

927 Trites, A.W. \& C.P. Donnelly. 2003. The decline of Steller sea lions Eumetopias 928 jubatus in Alaska: a review of the nutritional stress hypothesis. Mammal Review $929 \quad 33(1): 3-28$.

930 Torres, L.G. 2007. Top predator distribution and foraging ecology in Florida Bay. 931 PhD thesis. Duke University, Durham NC, USA.

932 Wells, R.S. \& M.D. Scott. 1994. Incidence of gear entanglement for resident 933 inshore bottlenose dolphins near Sarasota, Florida. Pages 629-650 in G. Perrin 934 and D. J. Barlow, eds. Gillnets and cetaceans. Report International Whaling 935 Commission.

936 Wells, R.S., S. Hofmann \& T.L. Moors. 1998. Entanglement and mortality of 937 bottlenose dolphins, Tursiops truncatus, in recreational fishing gear in Florida. 938 Fishery Bulletin 96:647-650. 
939 Wells, R.S., J.B. Allen, S. Hofmann, et al. 2008. Consequences of injuries on

940 survival and reproduction of common bottlenose dolphins (Tursiops truncatus)

941 along the west coast of Florida. Marine Mammal Science 24:774-794.

942 Wise, L., Silva, A., Ferreira, M., Silva, M.A. \& Sequeira M. 2007. Interactions

943 between small cetaceans and the purse-seine fishery in western Portuguese 944 waters. Scientia Marina 71, 405-412.

945 Yen, P.P.W., W.J. Sydeman \& K.D. Hyrenbach. 2004. Marine bird and cetacean 946 associations with bathymetric habitats and shallow-water topographies:

947 Implications for trophic transfer and conservation. Journal of Marine Systems $948 \quad 50: 79-99$.

949 Yousif, A. \& M.M. Sabrah 2004. Catchability of red mullets (Upeneus spp.) from

950 North West red sea during autumn. Egyptian Journal of Aquatic Research $951 \quad 30: 290-305$.

952 Zahri, Y., N. Abib, N. Elouamari \& B. Abdellaoui. 2004. Etude de l'interaction 953 entre le Grand dauphin et la peche á la senne coulissante en Méditerrané 954 Marocaine. Report of INRH, Nador, Morocco. 52 pp. 